\title{
Frequency of anemia in pregnant women of different age groups at Quetta: A hospital-based cross sectional study
}

\author{
Akhtar Bibi ${ }^{1}$, Asmatullah Kakar ${ }^{2 *}$, Fozia Shahwani ${ }^{3}$ and Farhat Iqbal ${ }^{4}$ \\ 1. Department of Zoology, Government Post Graduate Girls College, Cantt, Quetta-Pakistan \\ 2. Department of Zoology, University of Balochistan, Quetta-Pakistan \\ 3. Department of Gynecology, Bolan Medical College (BMC), Quetta-Pakistan \\ 4. Department of Statistics, University of Balochistan, Quetta-Pakistan \\ *Corresponding author's email: asmardanzai@yahoo.com
}

Citation

Akhtar Bibi, Asmatullah Kakar, Fozia Shahwani and Farhat Iqbal. Frequency of anemia in pregnant women of different age groups at Quetta: A hospital-based cross sectional study. Pure and Applied Biology. Vol. 8, Issue 2, pp1043-1050. http://dx.doi.org/10.19045/bspab.2019.80045

\begin{tabular}{llll}
\hline \hline Received: 12/01/2019 & Revised: 01/04/2019 & Accepted: 03/04/2019 & Online First: 06/04/2019 \\
\hline \hline
\end{tabular}

\section{Abstract}

The present study was conducted with the aimed to determine the frequency of anemia and lack of hemoglobin in human pregnancy at Bolan Medical College Hospital Quetta during 2017. As many as 625 pregnant women patients were examined, of these 350 were found anemic. Blood samples of randomly selected three hundred and fifty pregnant women of age group 17-44 years were analyzed, and was classified under first trimester (21), second trimester (58) and third trimester (271). The data was analyzed to estimate the frequency of anemia during pregnancy ranging from mild: $288(46.1 \%)$ to moderate: $54(8.6 \%)$ and severe: $8(1.3 \%)$. Findings revealed that anemia was found to be prevalent in third trimester (271) as compared to the second (58) and first (21) trimester of pregnancy. Chi-square test was applied at 5\% level of significance to check the association between age groups, parity and gestation age (G age). Significant association was found with anemic level at p-value $<0.001$ in age group and $\mathrm{G}$ age, whereas parity was not found associated with anemic level at $5 \%$ level of significance. The present study revealed that overall prevalence rate of anemia was 56\% which indicated high prevalence of this disease in the region. The study concluded that pregnant women are at high hazard of blood anemia. Fresh balanced diets rich in iron, folic acid and vitamin B12 are recommended for their health and fine growth of developing baby.

Keywords: Anemia; Frequency; Gestation-age; Hemoglobin; Parity; Quetta

\section{Introduction}

Anemia is common hematological problems in pregnancy have an impact on the hemoglobin $(\mathrm{Hb})$ concentrations. It has been a major public health concern over the past few decades [1]. Lack of iron is known to be the most common nutrition deficiency other than folic acid and vitamin B12 [2]. Anemia is defined by the Centre for Disease Control and Prevention (CDC) and World Health Organization [3] as $\mathrm{Hb}$ level $>11 \mathrm{gm} / \mathrm{dl}$. When $\mathrm{Hb} \%$ is $>7.0 \mathrm{gm} / \mathrm{dl}$ considered severe, if 7.0 to $9.9 \mathrm{gm} / / \mathrm{dl}$ (moderate), and mild when $\mathrm{Hb} \%$ falls between 10.0 to $10.9 \mathrm{gm} / \mathrm{dl}$. Globally, the poor countries and underprivileged groups suffer the most [4]. 
The highly affected population groups in developing countries are pregnant women $(56 \%)$, school age children (53\%), nonpregnant women $(44 \%)$, and preschool children (42\%) [5].

The world Health Organization [6] figured anemia prevalence among pregnant women at $41.8 / \%$ with the highest rate of incidence $(61.3 \%)$ found in pregnant women in Africa, and $(52.5 \%)$ among South East Asia. Africa is the most affected region among pregnancy ratio 17.2 million, which corresponds to around $30 \%$ of all maternal deaths. Anemia in pregnancy may also lead to premature births, low birth weight. Fetal impairment and kid's death [7].

Anemia is most prevalent in Asia. About half of all the anemic women live in the Indian subcontinent where $88 \%$ of them develop anemia during pregnancy [5]. It is associated with poor perinatal outcomes, especially in developing countries. Several of the studies have added to the outcome including one done at Aga Khan University Hospital (AKUH) in 2001-2002 [8]. In Pakistan, the prevalence of anemia among ever-married women aged 15 to 44 is reported to be $26 \%$ in urban areas and $47 \%$ in rural Areas. The prevalence of anemia among pregnant women living in urban areas is similar, ranging from $29 \%$ to $50 \%$ [9]. The present study was designed to determine the anemia prevalence and to analyze $\mathrm{Hb}$ concentration level as well as associated factors among different age groups pregnant females at BMC hospital, Quetta. There has been one study on prevalent type of anemia based on small sized sample conducted at different locality in this region of the province [10]. Therefore, the present study is being under taken to assess the burden of this problem in Quetta, so that effective measures can be taken to treat this condition and reduce morbidities associated with it.

\section{Materials and methods Area of study}

The present cross-sectional study was carried out during March 2017 t0 May 2017 at Bolan Medical Complex Hospital (BMCH) Quetta, Balochistan province, Pakistan to determine the prevalence of anemia and to estimate the level of hemoglobin and association of the various factors with anemia in pregnant women. The BMCH $\left(30.1908^{\circ} \mathrm{N}, 66.9739^{\circ}\right.$ $\mathrm{E})$ is the largest hospitals of the province comprise on 750 beds, situated in the western edge of the capital city and provides medical care to the majority of the inhabitants.

\section{Sampling size and procedure}

A sizable sample of 625 pregnant women of different age groups (17-44) was collected randomly in the present study. Out of 625 hospital based sampling, 350 pregnant females were diagnosed by the consultant Gynecologist with anemia. All pregnant women with pre-diagnosed anemia in their $1^{\text {st }}, 2^{\text {nd }}$ and $3^{\text {rd }}$ trimester were included in the study. All women were informed, that information would be used for only research purpose. Ethical approval for the study was obtained from the Medical Superintend (MS) and ethical committee of Bolan Medical Complex Hospital.

\section{Blood sample collection}

Blood samples were obtained with the consent of each selected participant (pregnant women) in the vials containing anticoagulant. The sample blood was analyzed for hemoglobin $(\mathrm{Hb} \%)$ level was estimated by Sahli's Method of hemoglobin estimation. $\mathrm{Hb}$ level below $11 \mathrm{gm} / \mathrm{dl}$ (WHO) was tagged as anemia during pregnancy and classified as mild (10.0-10.99 g/dl), moderate (7.0-9.9 $\mathrm{gm} / \mathrm{dl})$, and severe $(<7.0 \mathrm{gm} / \mathrm{dl})$ anemia.

\section{Data collection}

Pretested-Performa was developed with the help of the concerned consultant Gynecologist for the study of the anemic pregnant women reporting in the Obstetric/ Gynae OPD. The pretested-Performa was 
filled by the principle investigator. The outdoor patients Department (OPD) session was conducted weekly on every Wednesday and Friday. The data was collected over a period of Six (06) week and were checked for error. The collected data then were entered in SPSS 20.0 after proper coding of variables to tie the results.

\section{Statistical analysis}

The association between anemia in respondent pregnant women and associated factors like age, parity, gestation age, and trimester was also analyzed through cross tabulation using Chi-square test. Mean or median, SD and SD-error levels were thus calculated .The $p$-value of $<0.05$ was taken as significant.

\section{Results}

Among the pregnant women (625) recruited for the study, the overall prevalence of anemia observed was $56 \%$. The ratio of mild, moderate, and severe anemia was found to be $46.1 \%, 8.6 \%$, and $1.3 \%$ respectively among 350 adult females. Hence mild anemia was higher in terms of prevalence than other degree of severity. Data in table 1 indicated that women aged between 31-40 years were more anemic (62\%) than women lied between 17-30 years determined less anemic $(41 \%)$. The observed difference was found to be highly significant $(\mathrm{P}<0.0001)$ (Table 1$)$. While only $14 \%$ women above 40 (41-44) years of age were observed to be suffering from anemia. Variation in hemoglobin level was observed, minimum level of $\mathrm{Hb}$ detected was $5.3 \mathrm{gm} / \mathrm{dl}$, and highest was $10.9 \mathrm{gm} / \mathrm{dl}$ (Figure 1). Hb level of majority of the women $(75 \%)$ were found between 8.5-10.9 gm/dl. Only $3 \%$ of the women $\mathrm{Hb}$ levels were in range of $9.5-10.7 \mathrm{gm} / \mathrm{dl}, 22 \%$ were in range of 8.0-8.6 gm/dl.

The correlation between hemoglobin $(\mathrm{Hb})$ and age was examined, it revealed a positive correlation between them as there correlated value is -0.145 . The significance $p$-value is 0.007 is less than 0.01 .The correlation between $\mathrm{Hb}$ and parity was examined, it revealed a negative correlation between them as there correlated value is -0.046 . The significance p-value is 0.393 is greater than 0.01. Positive correlation between $\mathrm{Hb}$ and gestational age (Gage) was also found between them as there correlated value is 0.069 . The significance p-value is 0.199 is greater than 0.01 . Data in table 2 indicated the association between age groups, parity and Gage with anemic level. Age group and gestational age showed significant association statistically in term of severity of anemia (p-value <0.001), whereas the parity was not found associated with ratio of anemia at $5 \%$ level of significance.

\section{Discussion}

Anemia in pregnancy remains a major health problem worldwide, with an estimated $41.8 \%$ of pregnant women being diagnosed with anemia at some point in their gestation [11]. WHO [12] reported 52\% of the pregnant, and around $35 \%$ of the other women are anemic in developing countries. Prevalence of anemia among pregnant women (\%) in Pakistan was reported at 51.3\% in 2016, according to the World Bank collection of development indicators, compiled from officially recognized sources. A study conducted in Pakistan reported 35-40\% urban and $43-47 \%$ village women aged between $15-$ 44 year suffered from anemia, poor diet and deficient iron level was accounted for its cause during pregnancy [13].

In the present study frequency of anemia was $56 \%$ among 620 pregnant women of district Quetta (Figure 2). Out of 350 anemic women, $46.1 \%$ were mildly anemic, $8.6 \%$ and $1.3 \%$ were noted as having moderate, severe anemia (Figure 3). Hemoglobin level decreases due to increase in plasma level of blood during pregnancy [14]. In current study, lowest $\mathrm{Hb}$ level (5.3 gm/dl) was observed known to be alarming in pregnancy (Figure 1). Average $\mathrm{Hb}$ level ranged between 8.5-10.9 $\mathrm{gm} / \mathrm{dl}$ found in majority of the 
women. The present study were also found that pregnant women aged between 31-40 years were more anemic than between 17-30 years old, it was more prevalent 271 $(43.54 \%)$ in the third trimester (29-40 week) as shown in table 1 .

Anemia frequency in our study was lower than those reported from different parts of the country such as $96 \%$ in pregnant women of Multan, $75 \%$ in Faisalabad, $73 \%$ in Lahore, and $58.5 \%$ in Karachi respectively [15-18]. The later study showed severity of anemia as $80 \%$ mild, this is ever higher than that reported by other studies from Pakistan. However, unlike moderate anemic level ( $8.6 \%$ vs $15 \%)$ our findings are close to the prevalence of severe level of anemia such as $1.3 \%$ vs $2 \%$ respectively. Even though the present study showed $56 \%$ anemia frequency among the studied pregnant women, this is higher than $53.0 \%$ observed in Peshawar [19], 48.6\% in Rawalpindi [13], and 24\% in Karachi [20].

The present study is comparable with other studies done in Pakistan and especially in Khyber Pakhtoonkhwa (KPK) and Sindh provinces where $76.7 \%$ prevalence of anemia was recorded in distinct Mardan with $68.3 \%$ mild, $29.1 \%$ moderate, and $2.6 \%$ severe anemia [21]. Our finding is to some extent close to this study regarding the severe degree of anemia i-e $1.3 \%$ vs $2.6 \%$. Studies conducted in Abbottabad, Kohat and Karak districts (KPK) showed anemia prevalence in pregnant women to be $58 \%, 66.6 \%$, and $67.6 \%$ respectively [22-24]. Our study is similar partly to the former study in terms of prevalence (56\% vs $58 \%$ ), but due to large subject size (625 vs 100) our study is more genuine. In Hyderabad (Sindh) 90.5\% anemia prevalence was reported with observation that $75 \%, 14.8 \%$ cases of anemia were mild and moderate, severe anemia was lower $(0.7 \%)$ in this study [8] than the $2 \%$ to $7 \%$ reported for developing countries by WHO [25].

The ratio of anemia in pregnancy in other developing countries ranges from $35 \%$ to $81 \%$ [25-29]. Similar high rate of anemia (87\%) among 4775 pregnant women was found in a large study [30] conducted in India followed by $(86 \%)$ in Tanzania, (74\%) Nigeria, (46\%) Indonesia, (47\%) Philippins, (48\%) in Bangladesh [31], (38.4\%) in Malaysia [4], (43.2\%) in Vietnam [32] and (58.9\%) in Nepal [33]. More than half, 328 $(56.8 \%)$ pregnant women were anemic from the total (577) studied in Gode town, Eastern Ethiopia [34].This finding is in line with our study where $350 \quad(56 \%)$ anemia was determined in pregnant women. Recent statistics shows a prevalence of around $45 \%$ of $\mathrm{Hb} \%$ (Iron) lacking anemia in Pakistan, which is quite high realizing the failure of public health measures to control it [15]. According to WHO [25] statistics, it has been found that more than one-fifth of women in Pakistan suffer from anemia. At country level, awareness exists regarding this lasting health problem in the country as verified by several regional surveys [1]. 
Table 1. Level of degree of anemia among pregnant women of different age groups

\begin{tabular}{|c|c|c|c|c|}
\hline \multirow{2}{*}{ Age groups (years) } & \multicolumn{3}{|c|}{ Anemic Level } & \multirow{2}{*}{ P-value } \\
\cline { 2 - 4 } Age & Severe & Moderate & Mild & \\
\hline $17-30$ & & & & 0.0001 \\
\hline $31-40$ & $4(3 \%)$ & $16(13 \%)$ & $103(84 \%)$ & \\
\hline Above 40 & $1(1 \%)$ & $22(12 \%)$ & $162(87 \%)$ & \\
\hline Parity & $3(7 \%)$ & $16(38 \%)$ & $23(55 \%)$ & \\
\hline P0-PG & & & & 0.599 \\
\hline P1 - P4 & $0(0 \%)$ & $4(17 \%)$ & $20(83 \%)$ & \\
\hline$>$ P4 & $5(4 \%)$ & $18(14 \%)$ & $108(82 \%)$ & \\
\hline Gestational Age (weeks) & $3(2 \%)$ & $32(16 \%)$ & $160(82 \%)$ & \\
\hline $1^{\text {st }}$ Trimester(0-21) & $1(5 \%)$ & $3(14 \%)$ & $17(81 \%)$ & 0.090 \\
\hline $2^{\text {nd }}$ Trimester(13-28) & $3(5 \%)$ & $14(24 \%)$ & $41(71 \%)$ & \\
\hline $3^{\text {rd }}$ Trimester(29-40) & $4(1 \%)$ & $37(14 \%)$ & $230(85 \%)$ & \\
\hline
\end{tabular}

Table 2. Analysis of variance for hemoglobin $(\mathrm{Hb})$ against Age groups, Parity and Gage

\begin{tabular}{|c|c|c|c|c|}
\hline Age & Low age & Moderate age & Last age & Significance \\
\hline & $9.74 \pm 1.07^{\mathrm{a}}$ & $9.99 \pm 0.79^{\mathrm{b}}$ & $8.91 \pm 0.99^{\mathrm{c}}$ & $<0.001$ \\
\hline Parity & Group 1 & Group 2 & Group 3 & \\
\hline & $9.73 \pm 0.96$ & $9.67 \pm 1.11$ & $9.84 \pm 0.88$ & $>0.05$ \\
\hline G Age & Low & Medium & High & \\
\hline & $10.02 \pm 1.08^{\mathrm{a}}$ & $9.30 \pm 1.18^{\mathrm{b}}$ & $9.77 \pm 0.98^{\mathrm{a}}$ & $<0.001$ \\
\hline
\end{tabular}

Different superscripts at each row mean significantly different

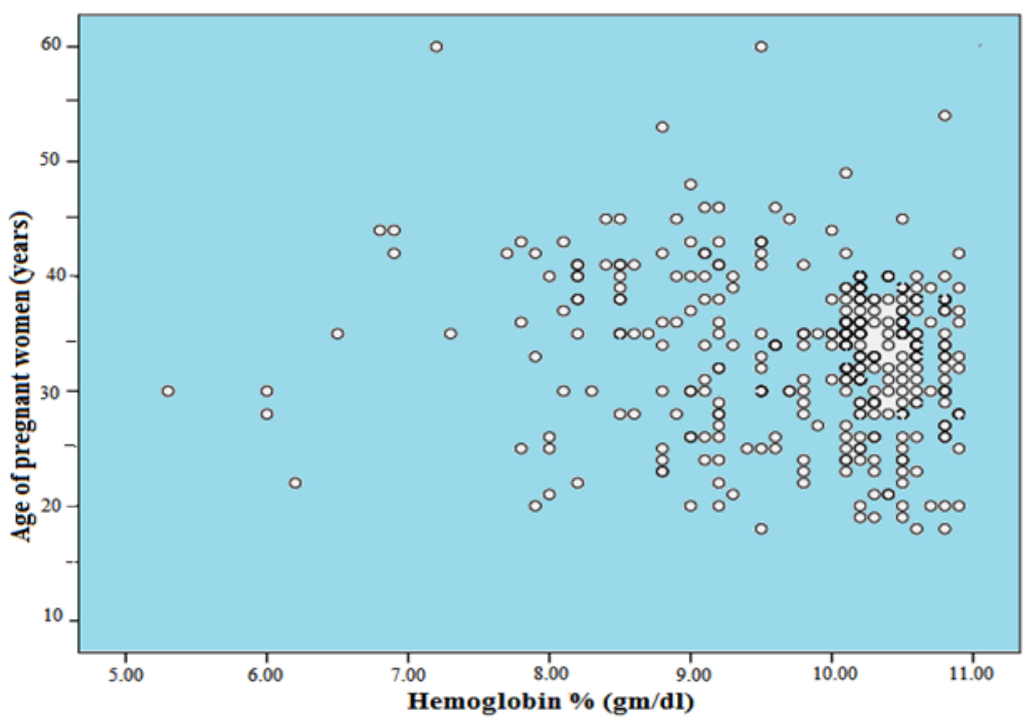

Figure 1. Association of Hemoblobin $(\mathrm{Hb} \%)$ with age of pregnant women estimated in the present study in 2018 


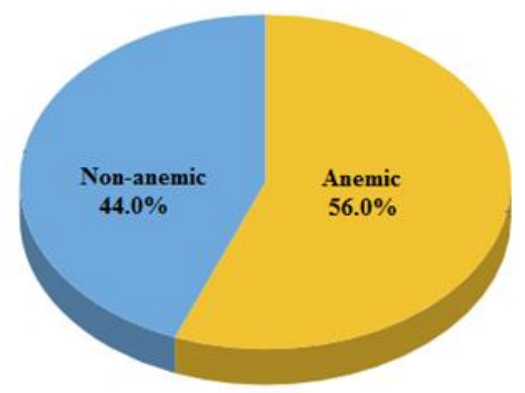

Figure 2. Distribution percentage of anemia assessed among pregnant women in the present study during 2018

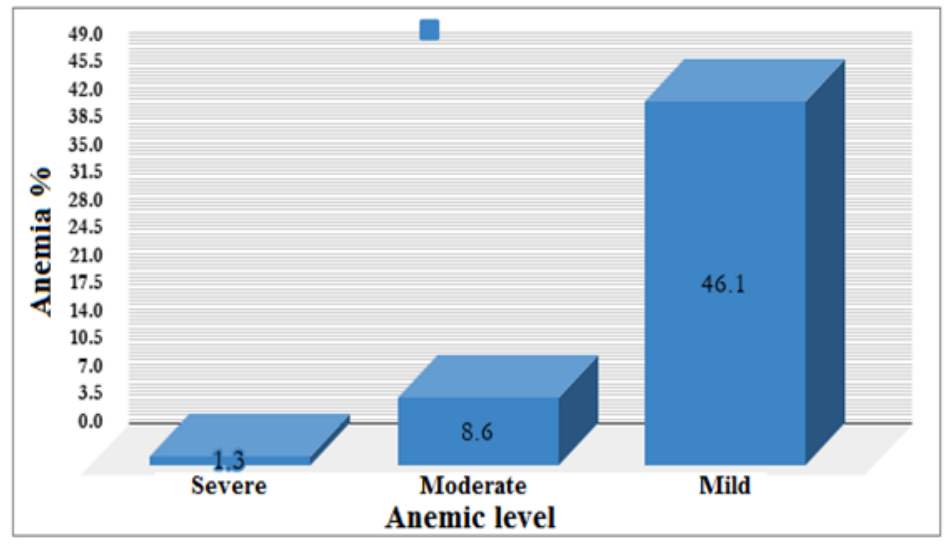

Figure 3. Degree of anemia severity among pregnant women determined in the present study during 2018

\section{Conclusion}

In the light of results obtained in this study it is concluded that anemia prevalence among pregnant women was high compared with pregnant women in other areas of Pakistan. Multiple factors like age, parity, and diet can determine the stores of iron in the women of child bearing age group. Trimester of current pregnancy, age, parity, $\mathrm{Hb}$ frequency were found to be significantly associated with anemia. Iron intake and special care during late pregnancy are recommended to reduce anemia. Further research on risk factors of anemia, which include rural residents, should be conducted to strengthen and broaden these findings.

\section{Authors' contributions}

Conceived and designed the experiments: A Bibi \& A Kakar, Performed the experiments: A Bibi \& F Shahwani, Analyzed the data: F Iqbal \& A Kakar, Contributed reagents/ materials/ analysis tools: F Iqbal \& A Bibi, Wrote the paper: Kakar.

\section{Acknowledgments}

The authors are thankful to Medical Superintendent (MS) of Bolan medical complex hospital (BMCH), Quetta for providing facilities. Thanks are due to staff and laboratory experts of Haematology unit for their honest cooperation. They would also like to extend their gratitude and admiration to senior staff of Gynae \& Obstetric unites of $\mathrm{BMCH}$ for enabling them to go through this 
research undertaking process. Their special thanks go to the study participants for their tendency to share their experience and giving time for the interview.

\section{References}

1. Mawani M, Ali SA, Bano G \& Ali SA (2016). Iron Deficiency Anemia among Women of Reproductive Age, an Important Public Health Problem: Situation Analysis. Reprod Syst Sex Disord 5: 187-193.

2. Stevens GA, Finucane MM, De-Regil LM, Paciorek CJ, Flaxman SR \& Branca F (2013). Nutrition Impact Model Study Group. Global, regional, and national trends in haemoglobin concentration and prevalence of total and severe anemia in children and pregnant and non-pregnant women for 1995-2011: a systematic analysis of population-representative data. The Lancet Global Health.

3. WHO (2005). Joint external evaluation tool: International Health Regulations.

4. Milman N (2015). Iron Deficiency and Anaemia in Pregnant Women in Malaysia. Still a Significant and Challenging Health Problem. J Preg Child Health 2(3): 168-176.

5. Siddiqui MS \& Siddiqui MK (2008) Public Health significance of iron deficiency anemia. Pak Armed Forces Med J 58(3): 315-327.

6. WHO and UNICEF, focusing on anemia: Towards an integrated approach for effective anemia control, WHO, Geneva, Switzerland, 2004.

7. Sifakis S \& Pharmakides G (2008). Anemia in Pregnancy, Annals New York Academy of Sciences.

8. Lone FW, Qureshi RN \& Emmanuel F (2004). Maternal anaemia and its impact on perinatal outcome in a tertiary care hospital in Pakistan. East Mediterr Health J 10: 801-807.

9. Baig-Ansari N, Badruddin SH, Karmaliani R, Harris H, Jehan I, Pasha
O, Moss M, Elizabeth M, Mc clure \& Golodenberg RL (2008). Anemia prevalence and risk factors in pregnant women in urban area of Pakistan. Food and Nutrition Bulletin 29(2): 132-139.

10. Ambreen Ijaz A, Tariq MM, Makai G, Najamunnisa, Rukhsana, Aqalmina, Ameen S, Rafeeq M, Saadullah J \& Ahmad Z (2014). The Study of Anemia in Relation to the Socio-Demographic Factors in Pregnant Females of Quetta, Balochistan. Pakistan J Zool 46(3): 885887.

11. Gupta A \& Gadipudi A (2018). Iron Deficiency Anaemia in Pregnancy: Developed Versus Developing Countries. Europian Med J Hematol 6(1): 101-109.

12. UNICEF/UNU/WHO (2001). Iron deficiency anemia: Assessment, prevention and control. Geneva, World Health Organization.

13. Khalid S, Hafeez A \& Mashhadi SF (2017). Frequency of pregnancy and its association with socio-demographic factors iin women visiting a tertiary care hospital in Rawalpindi. Pak Armed Forces Med J 67(1): 19-24.

14. Nazir G, Naz S, Ali S, Aziz S, Malik SA, Qari IH \& Irum S (2011). Anaemia: the neglected female health problem in developing countries. J Ayub Med Coll Abbottabad 23(2): 8-11.

15. Mahemunir A, Muhammad A \& Khan MI (2004). A study of anemia in pregnant women of railway colony, Multan. Pakistan J Med Res 43(1): 1114.

16. Anjum A, Manzoor M, Manzoor N \& Shakir HA (2015). Prevalence of anemia during pregnancy in district Faisalabad, Pakistan. Punjab Univ J Zool 30(1): 015020.

17. Sohail R, Zainab S \& Zaman F (2004) Prevalence of anaemia in obstetrical 
population. Ann King Edward Med Coll 10: $146-148$.

18. Samina Asghar S, Uzma Naz U, Faryal Awan F \& Awan A (2011). Obstetric outcome of iron deficiency anemia. Pak J Med Health Sci 5(2): 303-306.

19. Paracha PI, Hameed A, Simon J, Jamil A \& Nawab G (1997) Prevalence of anaemia in semi-urban areas of Peshawar, Pakistan: A challenge for health professionals and policy makers. J Pak Med Assoc 47: 49-5314.

20. Zehra T, Khan R A \& Qadir F (2014). Anemia in pregnancy a study of Karachi in a tertiary care center. Amer $J$ Phytomedi Clin Therap 10(10): 12241233.

21. Shams S, Ahmad Z, Wadood A (2017) Prevalence of Iron Defciency Anemia in Pregnant Women of District Mardan, Pakistan. J Preg Child Health 4: 356360.

22. Noreen S, Faisal NS, Shakeel AS, Khan S, Anhum AA \& Bukhari Z (2014). Prevalence of Anemia in Pregnant Women of District Abbottabad, Pakistan. Pak J Clinc Biomed Res 2(2): 12-16.

23. Riaz U, Ayaz S, Khader JA, Abdelslam NM \& Anwar M (2013) Prevalence and detection of anaemia (Iron Deficiency) in women population in Kohat Khyber Pakhtunkhwa. Pakistan. Life Sci J 10: 812-815.

24. Irfan U, Muhammad Z, Muhammad IK \& Mudassir S (2013) Prevalence of anaemia in pregnant women in district Karak, Khyber Pakhtunkhwa. Pakistan Int J Biosci 3: 77-83.

25. WHO, worldwide prevalence of anaemia 1993-2005: Global Database on Anaemia, WHO, Geneva, Switzerland, 2008.
26. Seshadri S (2001). Prevalence of micronutrient deficiency particularly of iron, zinc and folic acid in pregnant women in South East Asia. British $J$ Nutr 85(suppl 2): 87-92.

27. Shali T, Singh C \& Goindi G (20040. Prevalence of anemia amongst pregnant mothers and children in Delhi. Indian J Pediatr 71: 946.

28. Adam I, Khamis AH \& Elbashir MI (2005). Prevalence and risk factors for anaemia in pregnant women of eastern Sudan. Trans Royal Soc Trop Med Hyg 99: 739-43.

29. Ayoya MA, Spiekermann-Brouwer GM, Traore AK, Stoltzfus RJ \& Garza C (2006). Determinants of anemia among pregnant women in Mali. Food Nutr Bull 27: 3-11.

30. Toteja G S, Singh P, Dhillon BS \& Saxena BN (2006). Prevalence of anemia among pregnant women and adolescent girls in 16 districts of India. Food Nutr Bull 27(4): 311-315.

31. Brabin BJ, Hakimi M \& Pelletier (2001). An analysis of anemia and pregnancy related maternal mortality. $J$ Nutrition 131(2): 604-615.

32. Aikawa R, Khan NC, S.Sasaki S \& Binns CW (2006). Risk factors for iron deficiency anaemia among pregnant women living in rural Vietnam. Public Health Nutr 9(4): 443-448.

33. Shah BK \& Baig LA (2005). Association of anemia with parasitic infestation in pregnant Nepalese women: results from a hospital-based study done in eastern Nepal. J Ayub Med Coll Abbottabad 1: 5-9.

34. Addis K A \& Mohammad A (2014). Prevalence of Anemia and Associated Factors among Pregnant Women in an Urban Area of Eastern Ethiopia. Anemia 10: 561-567. 